\title{
Cultural Effects in Usability Assessment
}

\author{
Alvin Yeo \\ Computer Science Department \\ University of Waikato \\ Private Bag 3105, Hamilton, New Zealand \\ awy@cs.waikato.ac.nz
}

\begin{abstract}
A study is being conducted to identify factors that may affect results of usability evaluation techniques. Preliminary results based on eight subjects are described and then implications of the findings are discussed.
\end{abstract}

\section{Keywords}

usability testing, think aloud, cultural issues, Malaysia

\section{INTRODUCTION}

Nielsen [1] and Fernandes [2] caution that results of usability tests, conducted in the software's country of origin, may not be valid internationally. The software must be tested in the target market to ensure that the software is acceptable and do not cause offence to the target community. One of the issues software developers will need to contend with is aspects of culture that may impact on usability testing. Methods that work in the West, e.g. the United States (US), may not work in other cultures [3]. For example, Fernandes [2] describes lessons learnt by Claris Corporation in Japan:

- "Questions regarding how comfortable or how much they "like" the product were removed because they involved feeling and emotion which are issues that the Japanese are not accustomed to responding to.

- Japanese women spoke very softly. This put a huge premium on the quality of the microphone and where it was placed.

- Co-discovery techniques were used but they became problematic when people of differing status were put in the room together. In particular, women were found to talk very little when they were paired with a man." [2].

In Singapore, a subject actually broke down and cried when testing the software [3]. However, during the post-test interview, the subject was very positive about the software. This behaviour is believed to be attributed to the Eastern culture whereby it is "considered culturally unacceptable to criticise the designer directly or openly, as this may cause the designers to lose face" [3].

Thus, to ensure accurate usability tests' results, lessons from the above need to be taken into account. Otherwise, usability tests may add little to what is already known. Literature about cultural effects on usability techniques, such as the examples given, is sparse. This observation is quite surprising as US (the biggest exporters of software in the world) earns more than half of its revenue from outside the
US. For software to be successful, it is crucial to "know" your customers and potential users. Software developed and created for a particular locale would be potentially more successful than a generic product. As such, more studies need to be conducted to find out more about potential markets. One such potential market is the Asia Pacific region which accounted for US $\$ 1.4$ billion of US personal application software sales in 1996, an increase of $22 \%$ over 1995 [4]. The fastest growing markets were China with $81 \%$ sales growth over 1995, Malaysia 42\%, Japan 27\%, Thailand $24 \%$ and Korea $13 \%$. Further increase in these sales are expected in the future.

In this research, the study was conducted in Malaysia, the country of origin of the author. Malaysia has had a high economic growth rate of about $8 \%$ for the last decade and aims to achieve fully developed status by the year 2020 . The Malaysian Government has also initiated the Multimedia Super Corridor (MSC), "a vehicle to attract world class technology-led companies to Malaysia, and to develop local industries.". Commercial software development in Malaysia comprises mainly in-house development. There is hardly any locally developed software applications for the public. One reason is that Malaysians are English literate and thus are likely to use the popular software applications from US.

\section{RESEARCH QUESTIONS}

The aims of this research are to: identify the cultural factors that affect usability testing, examine how these cultural factors affect usability testing, and identify ways to improve usability testing by reducing the cultural effects. Furthermore, the author hopes to gain insights into software use by bilingual Malaysian users.

Results from this Malaysian study may be indicative of results in other Asian countries as Malaysia shares similar cultural attributes with its neighbours.

\section{METHOD}

To identify the cultural factors that may affect usability testing, data collected in an experiment have been scrutinised. In the experiment, expert spreadsheet users who are staff members of a Malaysian university, completed a set of tasks in a spreadsheet with a Bahasa Melayu (Malaysia's national language) interface. During the experiment, the users were required to think aloud (described as probably the most valuable usability engineering method) [6] and the session tape recorded. Also, the subjects' interactions (keystrokes) were recorded by a logging algorithm in the 